Reported management of threatened miscarriage by general practitioners in Wessex

SIR,-Dr C C Entwistle and colleagues from the regional blood transfusion centres at Oxford and Leeds are dismayed (17 October, $p$ 998) that a recent report (5 September, p 583) showed that $29 \%$ of Wessex general practitioners never gave anti-D to $R h(D)$ negative women after a complete abortion and $77 \%$ failed to do so for a threatened abortion. This appears to be in contrast with the guidance given by the Department of Health and Social Security ${ }^{1}$ and may be partly responsible for some women being $\mathrm{Rh}$ sensitised.

The implication is that general practitioners are failing to provide a necessary service. The matter, however, is not so simple. I have been in correspondence with my regional blood transfusion service (Trent) since 1982 about this problem, and Trent's advice, and possibly that of other regional blood transfusion services, has been that it is unnecessary to give anti-D prophylaxis to women whose threatened abortion is not severe or prolonged enough to warrant hospital admission. This advice overlooks the fact that there is no generally accepted treatment for early abortion (apart from Shrodker suture), so some women are not sent to hospital, particularly in a country area, unless complications ensue. It also overlooks the threatened abortion at home that becomes complete quite quickly and the woman who regards abortion as "natural" and wishes to stay at home.

Further to the regional blood transfusion service's advice, I have also been informed that the guidance contained in the DHSS recommendations in 1981 came as a surprise to a number of members of the committee that supposedly drew it up. Clearly, even in 1987 there is still no unanimity of opinion among workers in this subject. In 1982 I was also told that if every general practice held stocks of immunoglobulin (which would be necessary to provide an effective domiciliary service, particularly at weekends and bank holidays) the nation's supply might be depleted within the first month or two. This may not now be the case.

Dr Entwistle and colleagues are in a position to put their dismay to constructive use. The blood transfusion service needs to settle on agreed nationwide policy and to ensure that there are sufficient stocks of immunoglobulin for that policy to be effective.

Sleaford Medical Group,

Northgate, Sleaford, Lincs

1 Department of Health and Social Security, Scottish Home and Health Department, Welsh Office. Haemolytic disease of the unborm. London: HMSO, 1976. (Addendum 1981.)

\section{Detecting pneumococcal antigen in community acquired pneumonia}

SIR,-The recent leading article on community acquired pneumonia (31 October, p 1083) and the survey by the Research Committee of the British Thoracic Society and the Public Health Laboratory Service ${ }^{1}$ noted the value of sputum and urine examination for pneumococcal antigen in cases of community acquired pneumonia. The microbiological method for antigen detection in sputum used in this survey was counterimmunoelectrophoresis and this was found to be $86 \%$ sensitive for pneumococcal infection.

The advantage of early diagnosis of pneumococcal infection is obvious, but there are disadvantages in the use of counterimmunoelectrophoresis. It is labour intensive, suited particularly to batching tests, and therefore not ideal for emergency speci- mens. It also requires a limited amount of specialised equipment and certain technical skill.

Commercial antigen detection tests (Wellcogen and Phadebact) have been available for some time and are of value in detecting antigen in cerebrospinal fluid and urine. ${ }^{2}$ To date the manufacturers do not recommend their use in sputum analysis. In 1985 Whitby and others ${ }^{3}$ compared counterimmunoelectrophoresis, the Wellcogen latex agglutination, and Phadebact coagglutination for pneumococci directly on specimens of sputum. They found all three tests to be at least as sensitive $-67 \%, 71 \%$, and $74 \%$ respectively-and all were $98-99 \%$ specific; however, the sputum samples examined were not all from patients with community acquired pneumonia. Other workers showed counterimmunoelectrophoresis to be at least as sensitive as coagglutination. ${ }^{45}$ It seems commercial antigen detection may be a more convenient (and equally sensitive) means of detecting pneumococci in patients with pneumonia.

Department of Medical Microbiology,

E G SMYTH St George's Hospital Medical School, London SW17 ORE

Department of Microbiology,

Royal Free Hospital,

London NW3 2QG

1 Research Committee of the British Thoracic Society and the Public Health Laboratory Service. Community acquired pneumonia in British hospitals: a survey of aetiology, mortality, prognostic factors and outcome. $Q \mathcal{F}$ Med 1987;62: 195-220.

2 Ingram DL, Pearson AW, Occhiuti AR. Detection of bacterial antigens in body fluids with the Wellcogen Haemophilus influenza b, Streptococcus pneumoniae and Neisseria meningitidis (ACY W135) latex agglutination tests. f Clin Microbiol 1983; 18:1119-21.

3 Whitby M, Kristinson KG, Brown M. Assessment of rapid methods of pneumococcal antigen detection in routine sputum bacteriology. 7 Clin Pathol 1985;38:341-4.

4 Kalin M, Lindberg AA, Olausson EH. Diagnosis of pneumococcal pneumonia by coagglutination and counter immunoelectrophoresis of sputum samples. Eur $\mathcal{f}$ Clin Microbio 1982;1:91-6.

5 Edwards EA, Coonrod JD. Coagglutination and counter immunoelectrophoresis for detection of pneumococcal antigen in the sputum of pneumonia patients. I Clin Microbiol 1980;11: 488-91.

\section{Variations in admission rates}

SIR,-Mr G Bevan and Professor $R$ Ingram are correct in pointing out that both the treatment intensity and the referral process must be considered when allocating resources ( 24 October, p 1039). Treatment intensity is considered to be a characteristic of the district of treatment and applies independently of the patient's district of residence. Similarly, the referral rate is considered to be a characteristic of the district of residencefor instance, availability of primary care-and independent of the district providing the treatment.

If a third assumption is made it becomes possible to calculate both the treatment intensity and the referral rate from hospital activity analysis data. The assumption is that the relative rate of admission of female compared with male patients is constant irrespective of the district of residence or of treatment.

Catchment population calculation: patients admitted

\begin{tabular}{clccc}
\hline \multirow{2}{*}{$\begin{array}{c}\text { Health district of } \\
\text { residence }\end{array}$} & Sex & \multicolumn{2}{c}{ Health district of treatment } & \\
\cline { 2 - 4 } & Male & 30000 & 2 & Resident population \\
\hline 1 & Female & 28000 & 3600 & 330000 \\
1 & Male & 450 & 3840 & 390000 \\
2 & Female & 504 & 2376000 & 22000000 \\
2 & & 25000000 \\
\hline
\end{tabular}

The table shows a two district model in which district 2 represents the remainder of England. The data yield a unique (positive) solution: catchment populations of 661700 and 47058300 , a treatment intensity that is $20 \%$ greater in district 2 , a referral rate that is $10 \%$ greater in district 1 , and a female admission rate that is $80 \%$ of the male rate.

J J JONES

Department of Community Medicine,

Leicester LE1 6TP

\section{Greeks bearing gifts}

SIR,-Most of the arguments for and against and fairly represented in your columns, but the two most recent letters ( 7 November, p 1208) deserve further comment, since one typifies progress and one shows a lack of awareness.

Dr Rupert Fawdry highlights one scheme to bring together those health workers concerned with the follow up of a pregnant patient. Shared obstetric care is just one of the extended applications possible with general practice computerisation.

Dr John Robson, however, shows a total lack of awareness of modern computer software and, referring to the "Micros for GPs" scheme, seems to suggest that the modern automobile should be avoided simply because Henry Ford had a few problems with his Model T. The AAH Meditel software in fact contains extensive report creating facilities which cannot be described as "crude." If he has any doubts I would be more than pleased to arrange to demonstrate these for him. Quite rightly he asks what his patients will gain: quite simply, care from a practice with more time to treat them as a community of people rather than ill patients; care based on a practice able to identify and even prevent health problems from arising; a better audit of the prescription medicines they receive; more certain follow up of immunisation and other preventive procedures, etc.

Finally, I would remind Dr Robson that the practice owns its own data and it is simply not true to say that software design means that the data are inaccessible to the team. Our software and training are designed specifically to facilitate data access.

AAH Meditel Ltd,

IAN BLACK

Bromsgrove,

Worcestershire B60 2EW

SIR,-Dr D Maharaj and colleagues (19 September, p 693) draw attention to the risk of aluminium related osteodystrophy in patients with impaired renal function receiving high doses of albumin replacement solution contaminated with aluminium, and other studies have dealt with aluminium toxicity. ${ }^{12}$ We measured the aluminium content of 10 consecutive batches of our $20 \%$ albumin as well as one to four batches of the same preparation from 19 suppliers. general practice computerisation have been well

\section{Aluminium bone disease}


All determinations were done according to Gorsky and Dietz ${ }^{3}$ in the Institut Pasteur, Lyons, using a Perkin-Elmer atomic absorption spectrometer model 3030 with an HGA 600 graphite furnace and a Zeeman background correction system. The intra-assay and interassay coefficients of variation were less than $5 \%$.

Aluminium concentration in Mérieux albumin was the lowest $(1.03(\mathrm{SD} 0.13) \mu \mathrm{mol} / \mathrm{l})$. In the other products aluminium content showed a wide disparity ranging from $4 \cdot 1$ to $1301 \mu \mathrm{mol} / 1$ depending on batch and manufacturer.

The source of aluminium contamination in albumin solutions is not yet known. It might originate from the extraction of filters and filter aids used to clarify fractions obtained during the manufacturing process, or from containers, glass, or bottle caps. ${ }^{4}$

Albumin is usually separated from other plasma components by Cohn's or Cohn's modified method. Our product is the only one to be fractionated from placental blood, however, not from plasma. This led us to improve the purification procedure by including one more step in the fractionation process: an ion exchange on diethylaminoethanol dextran and adsorption chromatography on diethylaminoethanol derivatives of silica beads. ${ }^{5}$ Before chromatography aluminium was found at a low concentration ranging between 0.41 and $1.68 \mu \mathrm{mol} / \mathrm{l}$. It was no longer detectable after chromatography, although the protein concentration was nearly 10 times the initial value. The reappearance of a low but detectable aluminium concentration in the final albumin sample was explained by the fourfold increase in protein concentration caused by the last ultrafiltration step.

To prevent aluminium overloading, especially in patients with impaired renal function, the albumin solutions should contain very low amounts of aluminium. Chromatography is a useful additional step to the classical fractionation process to remove aluminium contamination.

R EL HABIB

Institut Mérieux

69348 Lyon Cedex 07

France

J P EYGONNET

1 Maher ER, Brown EA, Curtis JR, Phillips ME, Sampson B Accumulation of aluminium in chronic renal failure due to administration of albumin replacement solutions. $\mathrm{Br} \mathrm{Med} \mathcal{J}$ 1985;292:306

2 Milliner DS, Shinaberger JH, Shuman RN, Coburn JW. Inadvertent aluminium administration during plasma Inadvertent aluminium administration during plasma replacement solutions. N Engl f Med 1985;312:165-7.

3 Gorsky JE, Dietz AA. Determination of aluminium in biological samples by atomic absorption spectrophotometry with a graphite furnace. Clin Chem 1978;24:1485-90.

4 Milliner DS, Feldman F, Shinaberger JH, Colburn JW. Aluminium contamination of albumin replacement solutions. NEnglf Med 1985;312:1390.

5 Tayot JL, Tardy M, Gattel P. Ion exchange and affinity chromatography on silica derivatives. In: Curling J, ed. chromats of plas on silica derivatives. In: Curling J, ed. Methods of plasma

\section{Use of ${ }^{9 m}$ Tc labelled sucralfate in detection} of bowel disease

SIR,-It is unfortunate, but on chemical grounds not unexpected, that ${ }^{99 m} \mathrm{Tc}$ sucralfate failed to function as a diagnostically useful marker for lower gut ulceration when used by $\mathrm{Mr}$ A George and colleagues (5 September, p 578) after preparative catharsis with Picolax. An explanation of their observations may well involve the following.

While the main action of sucralfate is to bind to gastric mucosa and to granulation tissue in ulcer bases, some of it dissociates in aqueous solution at low $\mathrm{pH}$ to form sucrose sulphate and release aluminium ions. ${ }^{1}$ As this material moves down- wards in the intestine with a concomitant rise in pH above 5 aluminium hydroxide will be freshly precipitated in a highly surface active form, so that it will readily bind ions such as phosphate. ${ }^{2}$ At least some of this aluminium hydroxide is likely to remain in association with the parent ${ }^{99 m}$ Tc labelled sucralfate. Luminal "hot spots" thus probably indicate the occurrence of what is well known in another context as phosphate binding by aluminium based antacids. Such phosphate binding is used therapeutically in the treatment of chronic renal failure. The characteristic pattern of the " $699 \mathrm{~m}$ Tc sucralfate filled" colon with haustral pattern outlined ${ }^{3}$ may well reflect the luminal distribution of ${ }^{99 m} \mathrm{Tc}$ marked phosphate.

In the more acidic conditions of the stomach and proximal duodenum no such aluminium hydroxide would be formed, and no binding of phosphate would occur ( $\mathrm{R}$ W Cargill et al, unpublished observations), so that ${ }^{99 m}$ Tc labelled sucralfate acts as a reliable marker for ulceration only in the acid secreting stomach. Beyond the pylorus in the lower intestine it is likely to be more a marker for phosphate in the lumen than for ulceration of the gut. George et al may be correct in suggesting that ${ }^{99 m} \mathrm{Tc}$ sucralfate is not reliable as an ulcer marker in the lower gut unless the $\mathrm{pH}$ conditions there are rendered exceptionally lowthat is, $\mathrm{pH}<4$. Preparation with lactulose or mannitol is unlikely to achieve these values. Even then, however, phosphate binding to the lumina contents must greatly reduce its specificity and reliability.

Uptake of the labelled sucralfate by faecal material has already been implicated as causing confusion in this proposed diagnostic technique (31 October, $p$ 1134). We propose that this uptake comes about through phosphate binding.

\section{W K STEWART}

Department of Medicine,

Ninewells Hospital and Medical School, Dundee DD1 9SY

Department of Molecular and Life Sciences, Dundee College of Technology, Dundee DD1 1HG

1 Nagashima R, Yoshida N. Sucralfate, a basic aluminium salt of sucrose sulphate, I. Drug Res 1979;29:1668-76.

2 Larson EA, Ash SR, White JL, Hem SL. Phosphate bindin gels: balancing phosphate adsorption and aluminium toxicity. Kidney Int 1986;29:1131-5.

3 Dawson DJ, Khan AN, Miller V, Radcliffe JF, Shreeve DR. Detection of inflammatory bowel disease in adults and children: evaluation of a new isotopic technique. $\mathrm{Br} \mathrm{Med} \mathcal{F}$ 1985;291:1227-30.

\section{Fetal and neonatal mortality}

SIR,-The results of the survey from Curaçao (10 October, $p$ 894) show that babies of low birth weight are the most important factor in determining the neonatal mortality rate of a population. As Dr H I J Wildschut and others have pointed out, large reductions in perinatal mortality will come as a result of long term political and socioeconomic development, ${ }^{12}$ but it is nihilistic to assume that more immediate measures cannot improve the situation. The number of babies born in hospital implies that most Curaçao mothers have ready access to antenatal care and if this is adequate then in the short term it may be wiser to examine aspects of neonatal care.

There are two areas worthy of further consideration-asphyxia and infection.

Despite adequate antepartum and intrapartum care there will be babies who require resuscitation. ${ }^{3}$ Prompt and adequate neonatal resuscitation can prevent damage due to postnatal delay in achieving normal cardiac output, blood gas pressures, and respiratory function. Hypoxic-ischaemic encephal- opathy and other adverse effects of asphyxia may not always be fully recognised among concomitant problems in preterm or low birthweight infants but undoubtedly contribute to overall mortality. ${ }^{45}$

Infection - an important problem in neonatal care world wide-is relegated to the miscellaneous category. In developing countries mortality from neonatal sepsis has been estimated at 80 per 1000. In Papua New Guinea, where there is a comparable situation, offering secondary care and with a similar neonatal mortality, ${ }^{7}$ neonatal sepsis accounts for $25 \%$ of all deaths in secondary care nurseries. ${ }^{8}$ As with asphyxia, for preterm or low birthweight infants septicaemia may be the terminal insult. The initial description of the Curaçao study mentions blood culture analysis, but the results of these investigations are not apparent. If the organisms cultured from the lung are a true reflection of the invasive septicaemias experienced by newborn infants in Curaçao then this may need further investigation. Geographical and temporal variations of pathogens responsible for neonatal sepsis have been well described but the predominance of Pseudomonas spp and Klebsiella spp must be worrying. The high numbers of placentas with chorioamnionitis might also implicate antepartum or intrapartum infection as a major factor in the deaths of some of the preterm babies, and data from Addis Ababa suggested that ascending amnionitis can be a major cause of perinatal death.$^{10}$ Even in the tertiary care nurseries of developed countries there are still high death rates of 20 to $75 \%$ in treated cases ${ }^{11}$ so that preventive measures may be more fruitful than early diagnosis and treatment.

There are short term measures aimed at preventing asphyxia and infection which might help to decrease neonatal mortality in the population described.

Goroka Base Hospital,

Papua New Guinea

DONALD F MACGREgOR

1 Rinke CM. Infant mortality and the low birth weight infant. JAMA 1985;253:826.

2 Alberman E. Prospects for better perinatal health. Lancet 1980;i:189-92.

3 Russel G Lydon Y, Tunstall M. Antenatal prediction of neonatal asphyxia. Anaesthesia 1975;30:118.

4 Cabal LA, Devaskar U, Siassi B, Hodgman JE, Emmanouilides G. Cardiogenic shock associated with perinatal asphyxia in preterm infants. I Pediatr 1980;96:705-10.

5 Brown JK. Infants damaged during birth. In: Hull D, ed. Recent advances in paediatrics. Edinburgh: Churchill Livingstone, 1986:57.

6 Ebrahim GJ. Perinatal priorities in developing countries. In Ebrahim GJ, ed. Paediatric practice in developing countries. London: Macmillan Press, 1981:195-201.

7 Grant JP. Basic indicators. In: UNICEF. The state of the world's children. Oxford: Oxford University Press, 1986

8 Vince JD. Neonatal care in perspective: results of neonatal care at Port Moresby. Papua New Guinea Medical foumal 1987, 30:127-34.

9 Siegel JD, McCracken GM. Sepsis neonatorum. $N$ Engl f Med 1981;304:642-7.

10 Naeye RL, Tafari N, Judge D, Gilmour D, Marboe C. Amniotic fluid infections in an African city. J Pediatr 1977;90:965-70.

\section{HIV antigenaemia and prognosis}

SIR,-Dr Court Pedersen and colleagues and Dr F de Wolf and colleagues (5 September, p 567, 569) confirm that the persistence of human immunodeficiency virus (HIV) antigen in infected homosexual patients indicates a poor prognosis and even increases the risk of asymptomatic patients developing the acquired immune deficiency syndrome (AIDS). A similar tendency might be surmised for intravenous drug abusers, and we report here the preliminary results of a prospective study of intravenous drug abusers from Barcelona, which combined specific HIV antigen and antibody detection with an assessment of clinical state. The presence of HIV antigen was analysed ${ }^{1}$ in 